Article

\title{
Social Tipping Interventions Can Promote the Diffusion or Decay of Sustainable Consumption Norms in the Field. Evidence from a Quasi-Experimental Intervention Study
}

\author{
Joël Berger ${ }^{1,2}$ (1)
}

1 Institute of Sociology, University of Bern, Fabrikstrasse 8, 3012 Bern, Switzerland; joel.berger@soz.unibe.ch; Tel.: +41-31-631-48-27

2 Department of Economics, Kalaidos University of Applied Sciences, Jungholzstrasse 43 , 8050 Zürich, Switzerland

Citation: Berger, J. Social Tipping Interventions Can Promote the Diffusion or Decay of Sustainable Consumption Norms in the Field. Evidence from a Quasi-Experimental Intervention Study. Sustainability 2021, 13, 3529. https://doi.org/ $10.3390 /$ su13063529

Academic Editor: Fanli Jia

Received: 26 February 2021

Accepted: 19 March 2021

Published: 22 March 2021

Publisher's Note: MDPI stays neutral with regard to jurisdictional claims in published maps and institutional affiliations.

Copyright: (C) 2021 by the author. Licensee MDPI, Basel, Switzerland. This article is an open access article distributed under the terms and conditions of the Creative Commons Attribution (CC BY) license (https:// creativecommons.org/licenses/by/ $4.0 /)$.

\begin{abstract}
The diffusion of environmentally sustainable consumption patterns is crucial for reaching net carbon neutrality. As a promising policy tool for reaching this goal, scholars have put forward social tipping interventions (SOTIs). "Social tipping" refers to the phenomenon that a small initial change in a parameter of a social system can create abrupt, nonlinear change via self-reinforcing feedback. If this reduces the burden on the environment, it is of potential interest for environmental policy. SOTIs are attempts to create social tipping intentionally. SOTIs produce rapid norm changes in laboratory experiments. However, little is known about the potential of SOTIs in the field. This research reports on a field intervention promoting the consumption of hot beverages in reusable mugs instead of one-way cups, conducted at Swiss university cafeterias $(\mathrm{N}=162,523$ consumption decisions). Two SOTIs involved an appeal promoting sustainable consumption with regular feedback about the current prevalence of sustainable consumption. Two control treatments involved either the same appeal without feedback or no intervention. This research offers three key findings. First, SOTIs involving regular normative feedback can transform sustainable consumption from a minority behavior into a social norm within weeks. Second, tipping points in real-world environmental dilemmas may exceed the values found in recent laboratory experiments ( $\geq 50 \% \mathrm{vs.} \geq 25 \%$ ). Third, SOTIs can also promote the decay of sustainable consumption. By implication, the risk-free use of SOTIs requires deeper insights into the boundary conditions of these dynamics.
\end{abstract}

Keywords: conditional cooperation; environmentally friendly consumption; field study; intervention; social norm change; social norm diffusion; sustainable consumption; social tipping; tipping point

\section{Introduction}

The adoption of environmentally sustainable consumption patterns, for example, in transportation and nutrition, has been suggested by the Intergovernmental Panel on Climate Change (IPCC) as an important strategy for reaching carbon net neutrality by 2050 [1,2]. This suggestion raises a question: How can policy makers effect the fast and comprehensive social change necessary for establishing environmentally sustainable consumption patterns?

Social tipping has recently been proposed as a strategy for reaching this goal [3,4]. The term social tipping refers to the phenomenon that a small quantitative change in a parameter of a social system can create abrupt, nonlinear change in this social system via self-reinforcing feedback. This process is of interest for environmental policy when this change is linked to ecological change [5]. Thus, a policy maker may create social tipping intentionally to promote the diffusion of sustainable consumption norms $[3,4,6,7]$. In what follows, an attempt to create social tipping intentionally is called a social tipping intervention (SOTI).

A social norm is defined as a behavioral pattern to which individuals prefer to conform when a majority conforms to it and a majority believes that others should also conform 
to it [8]. As such, social norms regulate individual behavior, including consumption behavior $[9,10]$. A recent example of an emerging social norm is the spread of "flight shame" in Europe, propagated by the Fridays for Future movement with the aim of establishing rail travel as a behavioral standard [11].

The idea that SOTIs can promote the diffusion of sustainable consumption norms stems from this theoretical reasoning. Many environmental problems can be conceived of as cooperation problems in social dilemmas: social situations characterized by an inherent tension between public and private interest [12-14], here termed "environmental dilemmas". On the one hand, everyone benefits from a stable climate. On the other hand, there are individual incentives to withhold one's contribution to climate protection and freeride on the effort of others $[15,16]$. For example, if everyone switched from convenient short-haul flights to more environmentally sustainable, if less convenient, rain travel in a strategy of cooperation, the resulting reduction in emissions would be substantial. Nonetheless, when everyone follows their self-interest, regularly taking flights in a strategy of defection, global climate change might well bring humanity to the tragic end implied by Hardin's gloomy analysis [17].

However, since Hardin, substantial research has shown that many people are not only motivated by self-interest. Instead, around $40-60 \%$ of a sample typically cooperate in social dilemmas to the extent that others also cooperate, a behavioral tendency called conditional cooperation [18-20]. Conditional cooperators are also willing to sanction freeriders, incentivizing them to cooperate too $[19,21]$. There is ample evidence that conditional cooperation and peer sanctions jointly promote cooperation not only in laboratory experiments but also in real-world environmental dilemmas [22-25].

In game-theoretic terms, conditional cooperation and peer sanctions transform an environmental dilemma with the single equilibrium of mutual defection into a coordination game with two equilibria, mutual defection and mutual cooperation $[6,8,26,27]$. A third possibility is an unstable equilibrium in mixed strategies, in which cooperation and defection are each chosen with a specific probability [28]. In terms of the theory of system dynamics, that game represents a system with the two alternative stable states of mutual defection and mutual cooperation, and the unstable mixed-strategy equilibrium [29].

The central feature of a coordination game is that the incentives to adhere to a strategy, for example, cooperation, increase as the number of others choosing that strategy grows [30]. The presence of coordination incentives generates the conditions necessary for social tipping to occur $[6,8]$. Coordination incentives enable a minority's behavior change to tip aggregate behavior from the equilibrium of mutual defection or the equilibrium in mixed strategies to that of mutual cooperation under certain conditions, and threshold models of social dynamics can describe the corresponding social mechanism precisely, as elaborated in more detail elsewhere [27,31-35].

Threshold models center on the notion of an individual threshold, $\mathrm{q}_{\mathrm{i}}{ }^{*}$. A threshold is defined as the proportion of group members that have to adopt a new behavior for an individual to adopt that behavior. Thresholds vary across individuals and social contexts, and in an environmental dilemma, they depend on numerous factors, such as the strength of individuals' cooperative preferences or their pro-environmental values [35-37]. A key assumption of threshold models is that people regularly update their beliefs about the current proportion of those that have already adopted a new behavior, $\mathrm{q}_{\mathrm{t}}$. As soon as $\mathrm{q}_{\mathrm{t}}$, for example, the proportion choosing train travel over flights, reaches an individual's threshold, $\mathrm{q}_{\mathrm{i}}{ }^{*}$, this specific individual starts cooperating. This mechanism, called frequencydependent learning, is also in line with theories of cultural evolution $[38,39]$.

Given these assumptions, the prevalence of the new behavior, $q_{t}$, changes over time according to $\mathrm{q}_{t+1}=\mathrm{F}\left(\mathrm{q}_{\mathrm{t}}\right)$, where $\mathrm{F}$ is the cumulative distribution function of the individual thresholds $\mathrm{q}_{\mathrm{i}}{ }^{*}$. Depending on the form of a specific cumulative distribution function, a social tipping point can but need not exist. A tipping point has the property that, when this point is crossed, a self-reinforcing feedback dynamic is triggered. Ever more individuals then adopt the new behavior over time, thereby steadily strengthening the incentives for 
others to follow suit, until finally the new behavior is established as a social norm that is followed by a majority [31-35,40].

The promise of population-level social change brought about by a limited intervention changing the behavior of only a minority renders SOTIs a potentially attractive environmental policy tool. Nevertheless, there are no foolproof recipes for creating social tipping; indeed, research on social tipping and norm diffusion is still at an early stage and has pursued diverse strands. First, there are historical examples of rapid norm change that fit the pattern of social tipping nicely. Examples include the diffusion of non-smoking norms within a decade at the beginning of the century in Europe [41] and the rapid increase in the proportion of women at US universities in the 1970s [42]. Second, fascinating evidence from laboratory experiments demonstrates that a committed minority of only $25 \%$ to $35 \%$ can be sufficient to cross a tipping point and establish a new behavior as a social norm $[43,44]$. Third, simulation models predict that social tipping in socioecological systems can trigger both the diffusion and decay of social norms prescribing sustainable behaviors, with strong consequences for the environment [45-49].

However, little is known about the potential of SOTIs in the field. Extending the validity of these findings, this study reports results from a SOTI promoting the diffusion of sustainable consumption norms in natural field settings. The consumers at Swiss university cafeterias have the choice of buying hot beverages either in reusable mugs, with the inconvenient obligation of returning their mugs after coffee break, or in more convenient, if less sustainable, one-way paper cups: an environmental dilemma. There are individual incentives to choose one-way cups over reusable mugs at the cost of the environment. Globally, 16 billion paper cups are thrown away every year [50,51].

Although reducing waste is an important goal in itself, the primary aim of this paper is to answer this question: Can SOTIs, relying on the provision of regular normative feedback, trigger the diffusion of sustainable consumption norms in the field? A positive outcome should encourage similar interventions, with the aim of advancing sustainable consumption at scale.

To determine whether SOTIs can promote the diffusion of sustainable consumption norms in the field, a quasi-experimental intervention study was implemented in this way. The choice of reusable mugs over one-way paper cups at university cafeterias was promoted for environmental reasons; the choice is referred to here as sustainable choice and sustainable behavior. The study was conducted at four treatment locations. First, a SOTI was conducted in a location with a high pre-intervention level of sustainable choices $(40.9 \%)$, which provided favorable conditions for social tipping. Second, a SOTI was conducted at a location with a low pre-intervention level of sustainable choices $(21.3 \%)$, which provided less favorable conditions for tipping. A high initial prevalence of sustainable choices is more favorable because, ceteris paribus, the higher the initial proportion of sustainable choices, the more likely an intervention is to push the proportion of sustainable choices over the tipping point. The intervention took the form of a sign, prominently placed at the cafeteria counters, displaying a normative appeal to use mugs for environmental reasons. Repeated normative feedback was provided as information about the proportion of beverages currently sold in mugs. Third, an extended control treatment involved a normative appeal but no feedback provision. Fourth, a control treatment was implemented without intervention. The extended control treatment allowed the effect of regular feedback provision to be separated from the mere effect of focusing the consumers' attention on the issue of sustainable consumption with an appeal [52], and the control treatment without intervention allowed potential macrotrends in sustainable behavior to be captured independent of the intervention.

The idea of triggering social tipping with regular feedback provision derives from a specific assumption of the threshold model outlined. This is the assumption that individuals regularly update their beliefs about the current prevalence of sustainable choices and that they switch to the sustainable option once this prevalence crosses their individual threshold $[31,32,34]$. Normative feedback updated on a regular basis provides consumers 
with the information necessary to update their beliefs. Should the normative appeal boost the prevalence of sustainable choices at the beginning of the intervention, as intended, this initial boost can then create incentives for others with slightly higher thresholds to switch to the sustainable option. This further increase, when fed back to the consumers, induces switching in individuals with even higher thresholds, and the same logic applies to each subsequent round of normative feedback. In addition, as sustainable behavior spreads, so do social sanctions, creating incentives even for the more self-interested to switch to the sustainable option $[15,19,53-55]$. Therefore, repeated normative feedback bears the potential of releasing a self-reinforcing dynamic with the potential to establish a sustainable consumption norm.

The provision of normative but non-repeated feedback is also at the core of descriptive norm interventions in social psychology. Descriptive norms are defined as the predominant behavior in a specific context and population, and people tend to comply with descriptive norms $[52,56]$. Consequently, feeding back a descriptive norm to a population can increase conformity with this norm, and a number of interventions promoting sustainable behaviors rely on this mechanism [57-60]. Instead of increasing conformity with an existing norm, tipping aims at establishing a socially desirable behavior as a new norm.

\section{Materials and Methods}

\subsection{Set-Up}

Consumers at Swiss university cafeterias have two options when buying their coffee. They can buy coffee either in reusable mugs or in less sustainable one-way paper cups. Because the more environmentally sustainable option comes with the liability of returning the mugs to the cafeteria after consumption, the choice gives rise to an environmental dilemma. Pre-intervention, $65 \%$ of all hot beverages were consumed in paper cups, and more than 95,000 paper cups were used during the time under investigation. This environmental dilemma provides an ideal ground for testing SOTIs that promote the diffusion of a sustainable consumption norm in the field.

\subsection{Treatments}

The quasi-experimental design involves four treatment conditions, summarized in Table 1. First, an intervention treatment combines a normative appeal with regular normative feedback, conducted at a location with a relatively high (40.9\%) pre-intervention prevalence of sustainable choices (Feedback/high). Second, an identical intervention treatment was conducted at a location with a relatively low (21.3\%) initial prevalence of sustainable choices (Feedback/low). Third, an extended control treatment involved an intervention with an appeal but no normative feedback (Control/appeal). Fourth, a control treatment was implemented without intervention (Control).

The treatments were assigned as follows. The cafeteria operator indicated its four largest cafeterias, and it happened that two cafeterias had a high level of mug use and two had a low level of mug use. Because the initial level of sustainable choices likely impacts the potential for tipping, one of the locations with a high level of sustainable choices and one of the locations with a low level of sustainable choices were randomly selected for the feedback interventions. Of the two remaining locations, one had a high level of sustainable choices and the other had a low level. These locations were assigned randomly to either the Control/appeal treatment or the Control treatment. The two feedback treatments were located in one city, Zurich, and within this city, they were located in geographically distant university buildings. The two control treatments were located in another city, Bern, again located in separate buildings. 
Table 1. Treatments.

\begin{tabular}{cccc}
\hline Treatment & Intervention & $\begin{array}{c}\text { Prevalence of Sustainable } \\
\text { Choices, Pre-Intervention }\end{array}$ & $\begin{array}{c}\text { No. Beverages Sold during } \\
\text { Observation Period }\end{array}$ \\
\hline Feedback/high & $\begin{array}{c}\text { Appeal + } \\
\text { normative feedback } \\
\text { Appeal + }\end{array}$ & high $(40.9 \%)$ & 63,434 \\
Feedback/low & normative feedback & low $(21.3 \%)$ & 37,901 \\
Control/appeal & Appeal & high $(53.3 \%)$ & 33,116 \\
Control & None & low $(21.9 \%)$ & 28,072 \\
\hline Total & & & 162,523 \\
\hline
\end{tabular}

Note: Prevalence of sustainable choices is defined as the proportion of hot beverages sold in mugs at a certain location and time. Feedback/high and Feedback/low were conducted in cafeterias located in separate university buildings of one Swiss city, Zurich. Both intervention treatments involved signs promoting the use of mugs (appeal) and information about the local percentage of mug use in the previous week (normative feedback), which was updated on a weekly basis. Control/appeal and Control were conducted in cafeterias located in separate university buildings in another Swiss city, Bern. Control/appeal involved an appeal but no feedback. No intervention was conducted in the Control treatment. The data were provided by the cafeteria operator.

\subsection{Materials}

A sign was prominently posted at every cafeteria counter (see Figure A1 in the Appendix A). In the background, the sign showed a large green mug at the top and several small, crumpled paper cups at the bottom as an eye catcher. The foreground displayed a normative appeal: "Use mugs instead of paper cups, for the sake of the environment". In the Feedback/high and Feedback/low treatments, the sign also displayed a normative feedback of the form "1st week of October. $22 \%$ are using mugs. Join them!". The information about the current proportion of beverages sold in mugs was updated weekly during the intervention period, and it referred to the local purchase decisions of the previous week. In the Control/appeal location, the signs were identical except that they displayed no normative feedback. No signs were posted at the Control location.

\subsection{Procedures}

During the observation period of 14 weeks, corresponding to one semester, the cafeteria operator reported the location-specific numbers of hot beverages sold and paper cups used on a weekly basis. The sample comprises every individual who bought at least one hot beverage at one of the four cafeterias during the observation period. In total, 164,892 hot beverages were sold. The total number of cafeteria visitors is unknown, but certainly smaller than 164,892 , because many customers, typically students and university employees, are regular ones. The dependent variable is the proportion of hot beverages bought in mugs, called sustainable choices. No data were collected on the backgrounds of the customers.

The observation period started simultaneously at all four locations, and it was structured in three periods. During weeks 1 to 3, called the pre-intervention period, data were recorded, but no interventions were implemented. At the beginning of week 4 , the intervention period started, and it lasted for eight weeks (weeks 4 to 11 of the observation period). The signs were placed prominently at the three locations involving an intervention at the beginning of week 4 . At the beginning of week 12 , the post-intervention period started. All signs were removed before the start of week 12, but data were still recorded for another three weeks (weeks 12 to 14).

\section{Results}

Did trends in sustainable choices differ before, during, and after intervention in the treatments? To answer this question, treatment-specific linear regression models were calculated with robust standard errors. The dependent variable was the period-specific proportion of sustainable choices. As predictors, three splines, named Pre-intervention (weeks 1-3), Intervention (weeks 4-11), and Post-intervention (weeks 12-14), were entered 
into the regression to capture linear trends in these phases [61]. The same terms are also used when referring to the Control treatment for reasons of convenience.

In total, 164,892 hot beverages were sold and over 95,000 paper cups were used during the observation period. The following analyses are based on a reduced sample of 162,523 purchase decisions because in week 9 of the observation period, the provider mistakenly reported a number of paper cups used in the Control treatment that exceeded the number of beverages sold, and the correct numbers could not be recovered subsequently. Therefore, the 2369 purchase decisions from week 9 of the Control treatment were excluded from the analyses. Refer to Table A1 in the Appendix A for descriptive statistics.

Figure 1a summarizes the dynamics in the Feedback/high treatment, and Table 2, column 1 , lists the corresponding regression output. An average prevalence of $40.9 \%$ sustainable choices in the three weeks preceding the intervention followed no systematic trend $(b=-0.002, t=-0.05, p=0.965,95 \%$ confidence interval $(\mathrm{CI})(-0.083,0.080))$. Following this, sustainable behavior jumped statistically significantly $(b=0.043, t=6.35, p=0.000$, CI $(0.028,0.080))$ by 32.7 percentage points to $73.6 \%$ in the final week of the intervention. Post-intervention, sustainable choices remained considerably above pre-intervention levels at an average of $63.8 \%$, although with a negative tendency $(b=-0.047, t=-3.78, p=0.004$, CI $(-0.074,-0.019))$. Notably, the sustainable choice was transformed from a minority behavior to a majority behavior $(64.6 \%)$ in the third week of the intervention, week 6 of the observation period.

This strong, abrupt increase fits the pattern of social tipping nicely. Although no data were gathered that would allow predicting social tipping points in advance of the intervention, we can speculate about its location post hoc. Figure 1a suggests that a social tipping point was crossed between weeks five and six, where the prevalence of sustainable consumption jumps from $40.9 \%$ to $64.6 \%$. As sustainable consumption had reached $48.7 \%$ already pre-intervention, in week two, without rising further thereafter, we can narrow the range down to roughly $50-65 \%$.

(a)

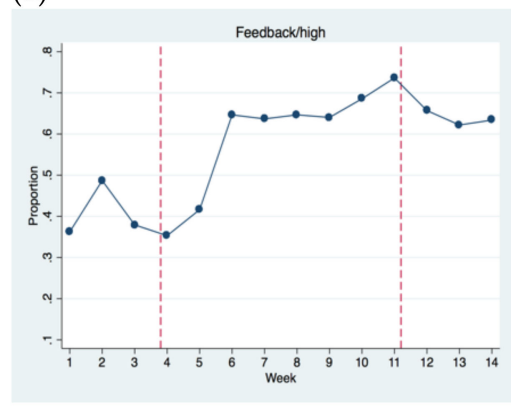

(c)

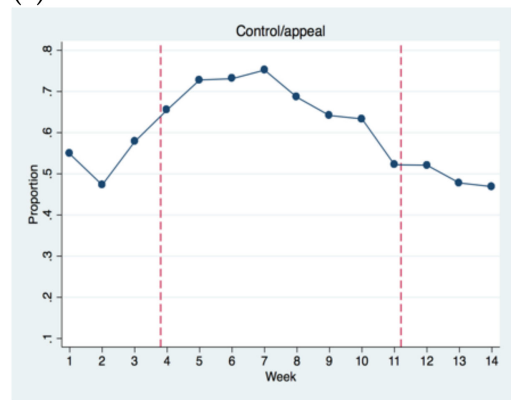

(b)

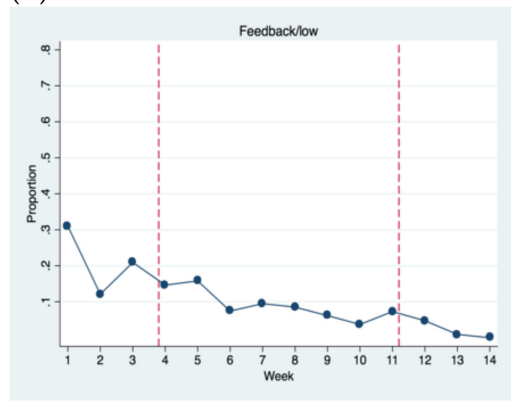

(d)

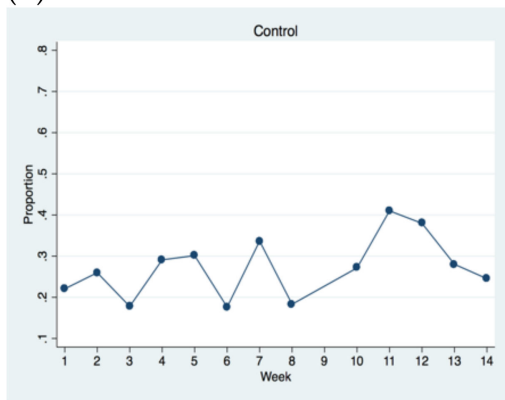

Figure 1. Prevalence of sustainable choices across treatments: (a) Feedback/high, (b) Feedback/low, (c) Control/appeal, (d) Control. Vertical dashed lines: begin and end of the intervention period. 
Table 2. Treatment-specific dynamics.

\begin{tabular}{|c|c|c|c|c|}
\hline & $\begin{array}{c}(1) \\
\text { Feedback/High }\end{array}$ & $\begin{array}{c}(2) \\
\text { Feedback/Low }\end{array}$ & $\begin{array}{c}\text { (3) } \\
\text { Control/Appeal }\end{array}$ & $\begin{array}{c}(4) \\
\text { Control }\end{array}$ \\
\hline Pre-intervention & $\begin{array}{c}-0.00166 \\
(-0.05)\end{array}$ & $\begin{array}{l}-0.0545 \\
(-1.79)\end{array}$ & $\begin{array}{l}0.0920 \\
(2.05)\end{array}$ & $\begin{array}{l}-0.0119 \\
(-0.48)\end{array}$ \\
\hline Intervention & $\begin{array}{c}0.0427^{* * *} \\
(6.35)\end{array}$ & $\begin{array}{c}-0.0140 * \\
(-2.70)\end{array}$ & $\begin{array}{c}-0.00701 \\
(-0.67)\end{array}$ & $\begin{array}{c}0.0164 \\
(1.96)\end{array}$ \\
\hline Post-intervention & $\begin{array}{c}-0.0468^{* *} \\
(-3.78)\end{array}$ & $\begin{array}{l}-0.0143 \\
(-2.03)\end{array}$ & $\begin{array}{c}-0.0600 \text { * } \\
(-2.88)\end{array}$ & $\begin{array}{l}-0.0283 \\
(-1.39)\end{array}$ \\
\hline Constant & $\begin{array}{c}0.406^{* * *} \\
(4.66)\end{array}$ & $\begin{array}{c}0.320 * * \\
(3.68)\end{array}$ & $\begin{array}{c}0.401^{* *} \\
(3.55)\end{array}$ & $\begin{array}{c}0.250 * * * \\
(5.61)\end{array}$ \\
\hline $\mathrm{R}^{2}$ & 0.806 & 0.810 & 0.545 & 0.318 \\
\hline
\end{tabular}

Note: Regression models with the proportion of sustainable choices at a given time period and location as dependent variables. Robust standard errors were used. The time periods were coded as splines with 14 aggregate observations per location (13 in the Control treatment) based on a total of 162,523 purchase decisions (the data were provided by the cafeteria operator). ${ }^{*} p<0.05,{ }^{* *} p<0.01,{ }^{* * *} p<0.001$; $\mathrm{t}$ statistics in parentheses.

It is also worth mentioning that the onset of the positive time trend coincides with the start of the intervention, and the switch from a positive to a negative trend coincides with the end of the intervention; this pattern corroborates the interpretation that the intervention, and not a factor independent of the intervention, generated the dynamics observed.

A clear trend was also observed in the Feedback/low treatment, although in the opposite direction (Figure 1b). Starting from a pre-intervention average of $21.3 \%$, sustainable choices decreased steadily by a total of 14 percentage points during the eight weeks of the intervention to $7.3 \%$ in the final week of the intervention, and even undershooting $2.0 \%$ post-intervention. The regression results (Table 2, column 2) indicate a negative, statistically insignificant, tendency pre-intervention $(b=-0.055, t=-1.79, p=0.104, \mathrm{CI}(-0.122,0.013))$, a negative, statistically significant trend during the intervention $(b=-0.014, t=-2.70$, $p=0.022, \mathrm{CI}(-0.026,-0.002))$, and a statistically insignificant tendency post-intervention $(b=-0.014, t=-2.03, p=0.07, \mathrm{CI}(-0.048,0.019))$. The pattern of a statistically insignificant negative net trend pre-intervention followed by an almost monotonous, statistically significant decline during the intervention suggests that the intervention either triggered a negative dynamic or, at least, amplified an existing negative tendency. The possibility that normative feedback can produce destructive dynamics is addressed in the discussion.

In the Control/appeal treatment (Figure 1c), sustainable choices follow an inverted Ushaped pattern, starting from a pre-intervention average of $53.5 \%$, peaking at $75.2 \%$ in week 7 , the fourth week of the intervention, and then steadily falling back to pre-intervention levels (52.2\% in the last week of the intervention, $48.9 \%$ on average post-intervention). Regression analyses (Table 2, column 3) point to the presence of a positive time trend pre-intervention, although this trend does not attain the $5 \%$-level of significance $(b=0.092$, $t=2.05, p=0.068, \mathrm{CI}(-0.008,0.192))$. The inverted U-shaped trend during the intervention results in a zero-net effect $(b=-0.007, t=0.67, p=0.519, \mathrm{CI}(-0.030,0.016))$, followed by a statistically significant post-intervention decline $(b=-0.060, t=-2.88, p=0.016$, CI $(-0.106,-0.014)$ ). Overall, the intervention involving an appeal but no normative feedback either had no effect or amplified a pre-existing positive trend. If the latter was the case, the reinforcing effect of the intervention did not last because sustainable choices fell back to initial levels during the second half of the intervention period. This result is in line with a recent meta-analysis that reported small and transient effects for interventions using normative appeals alone in promoting environmentally sustainable behaviors [62].

Finally, in the Control treatment without intervention, sustainable choices amounted to a pre-intervention average of $21.9 \%$, to an average of $34.1 \%$ in the last three weeks of the 
intervention, and to a post-intervention average of $30.2 \%$ (Figure 1d). Overall, sustainable behavior fluctuated substantially, even in the absence of an intervention, although without clear direction or statistically significant trend (Table 2, column 4) in pre-intervention $(b=-0.0119, t=-0.48, p=0.643, \mathrm{CI}(-0.068,0.0443))$, intervention $(b=0.016, t=1.96$, $p=0.081, \mathrm{CI}(-0.003,0.035))$ and post-intervention $(b=-0.0283, t=-1.39, p=0.199$, CI $(-0.074,0.018))$ periods.

In sum, strong monotonous trends with positive and negative slopes were observed in the Feedback/high and Feedback/low treatments, respectively, whereas no persistent trends were observed in either of the Control treatments. At the same time, nontrivial fluctuation was observed even in the Control treatment without intervention, a finding that raises a question: Could a trend, independent of the intervention, have contributed to the strong positive trend in the Feedback/high treatment or to the clear negative trend in the Feedback/low treatment? To test for this possibility, a difference-in-difference regression model was devised to compare the trends between the feedback treatments and the control treatment $[63,64]$. This statistical model controls both for all time-invariant confounders via location-fixed effects and for potential trends at the national level or higher via comparison with the Control treatment without intervention.

A comparison of the Feedback/high treatment with the Control treatment replicates the main results of no statistically significant pre-intervention trend (Feedback/high $\times$ pre-intervention $b=0.010, t=0.19, p=0.847, \mathrm{CI}(-0.097,0.117))$ and a strongly positive, statistically significant trend during the intervention (Feedback/high $\times$ intervention, $b=0.026, t=2.33, p=0.025$, CI $(0.004,0.049)$ ) (refer to Table A2 in the Appendix A for details). The pattern found for the Feedback/low treatment also replicates, with no preintervention trend (Feedback/low $\times$ pre-intervention, $b=-0.043, t=-0.81, p=0.425$, $\mathrm{CI}(-0.149,0.064))$, and a statistically significant negative trend during the intervention (Feedback/low $\times$ intervention, $b=-0.030, t=-2.70, p=0.010, \mathrm{CI}(-0.053,-0.008)$ ).

While the difference-in-difference regression controls for trends at the national level or higher, it cannot rule out the possibility of time-variant confounders at the subnational level, because the two feedback treatments were located in one city of the country and the two control treatments were located in another city of the same country. Nevertheless, as the onset of the positive trend in the Feedback/high treatment fits the onset of the treatment period perfectly, it is highly plausible that the intervention itself, rather than an independent trend, is responsible for the results. The evidence in the Feedback/low treatment is somewhat less conclusive, as a negative tendency was already present pre-intervention. It is possible that the intervention amplified this pre-existing trend rather than giving rise to a negative dynamic independently of the pre-existing trends. Taken together, these results dispel the concern that treatment-independent trends explain the results observed in the two Feedback intervention treatments. Finally, it is worth noting that the explained variance is 2.5 times higher in the Feedback/high and Feedback/low conditions $\left(\mathrm{R}^{2}=0.806\right.$ and 0.810 , respectively) than in the Control treatment $\left(\mathrm{R}^{2}=0.318\right)$ and 1.5 times higher than in the Control/appeal treatment $\left(\mathrm{R}^{2}=0.0545\right)$. This finding additionally strengthens the argument that the feedback interventions systematically influenced consumption choices (Table 2, columns 1-4).

In sum, the results convincingly show that regular provision of normative feedback can promote positive tipping dynamics under favorable conditions. The results also suggest that regular feedback can provoke, or at least amplify, negative dynamics under less favorable conditions.

\section{Discussion}

This research provides three key findings. First, we can intentionally create social tipping not only in the lab $[43,44]$ but also in the field. Practical SOTIs use the provision of regular normative feedback about the current prevalence of a target behavior in a population to this population. In one treatment location, an initial prevalence of $40.9 \%$ sustainable choices pre-intervention rose to an average of $71.1 \%$ in the last three weeks of the inter- 
vention. Repeated normative feedback established the sustainable choice as a social norm, and this norm remained post-intervention. Second, in the same treatment location, the social tipping point lay between ca. $50 \%$ and $65 \%$, which considerably exceeds the values so far observed in the laboratory $(25-35 \%)[43,44]$. Third, repeated normative feedback can also promote destructive dynamics under unfavorable conditions. In a second treatment location with only $21.3 \%$ sustainable choices pre-intervention, sustainable behavior fell to an average of $5.5 \%$ by the end of the intervention-a finding that corroborates predictions from simulation models $[45,46,48]$.

Destructive dynamics, called a "boomerang effect", have also been reported in earlier studies using one-time normative feedback $[59,65,66]$. This boomerang effect can be explained by threshold models: Those individuals who, pre-intervention, hold the incorrect belief that sustainable behaviors would exceed their thresholds switch from sustainable behaviors to unsustainable ones in response to the normative feedback. In contrast, those individuals who, pre-intervention, hold the incorrect belief that sustainable behaviors are below their thresholds switch from unsustainable behaviors to sustainable ones in response to the normative feedback [67]. Depending on which effect predominates, normative feedback has either a positive or negative net effect. Should a first round of feedback produce a boomerang, this can release a destructive dynamic whose final outcome can be the total collapse of sustainable behavior.

A major limitation of this research is the quasi-experimental nature of the intervention and the small number of intervention sites. The conclusion that the direction of the triggered dynamic - positive or negative-primarily depended on the initial level of mug usage is therefore only suggestive. Future research should increase the number of treatment locations and also collect individual-level data, for example, information on social status, social preferences, or environmental attitudes. This information is potentially useful for predicting individual thresholds and social tipping points [35], and also for ruling out potential confounders.

\section{Conclusions}

This research demonstrates that that we can intentionally create social tipping in the field and that tipping dynamics can promote either the diffusion or decay of sustainable behaviors. Consequently, using SOTIs as an environmental policy tool, as recently suggested $[3,4,6,7]$, could indeed be fruitful. However, policy makers should be aware that SOTIs bear both considerable constructive and destructive potential. They should also be aware that tipping points in real-world environmental dilemmas may lie considerably above the values found in recent laboratory experiments, suggesting more effort may be needed to activate social tipping dynamics than previous research suggests.

Policy makers could use SOTIs at lower risk if they were capable of predicting tipping points. Therefore, future research should put forward according methods, a challenging endeavor both in the natural sciences [29,68-71] and in the social sciences [5,29]. Nevertheless, recent advances are encouraging. Using threshold models [31-34], Efferson et al. (2020) precisely outlined conditions favorable and unfavorable for SOTIs [40], and Andreoni et al. (2020) predicted social tipping points in the lab with 96\% accuracy [44]. We may manage to measure individual thresholds in the field, at least approximately, for example, with stated-choice methods from survey methodology [25,72] or with experimental games [73]. Combining such field data with threshold models could then approximately predict social tipping points in the field.

Funding: This project was funded by a Swiss National Science Foundation grant (Investigating Signaling Theory Explanations of Pro- Environmental Behavior by Means of Laboratory and Field Experiments [P0EZP1_148998]).

Institutional Review Board Statement: Not applicable.

Informed Consent Statement: Not applicable. 
Data Availability Statement: Data available in a publicly accessible repository that does not issue DOIs. The data are available here: https:/ / www.researchgate.net/profile/Joel-Berger-3/publications (accessed on 22 March 2021).

Acknowledgments: Many thanks to Fabio Triulti and to the employees of the ZfV-Gastronomiegruppe for their great support and for making this research possible.

Conflicts of Interest: The author has no conflict of interest to disclose.

Short Biography of Author: Joël Berger is a senior research at the Institute of Sociology, University of Bern, and at the Kalaidos University of Applied Sciences, Switzerland. Before that, he was a research fellow at the Universities of Utrecht and Groningen and a postdoctoral researcher at the University of Zurich. He received his PhD in Sociology at ETH Zurich in 2016. Joël Berger is interested in how institutions and social norms impact human behavior and how these behaviors then form dynamics and patterns on the organizational and societal levels. This research applies to questions of behavior design and sustainable transformation.

\section{Appendix A}

Table A1. Descriptive results.

\begin{tabular}{cccc}
\hline Treatment & Pre-Intervention & $\begin{array}{c}\text { Prevalence of Sustainable Choices (\%) } \\
\text { Last Three Weeks of } \\
\text { the Intervention }\end{array}$ & Post-Intervention \\
\hline Feedback/high & 40.9 & 71.1 & 63.8 \\
Feedback/low & 21.3 & 5.5 & 1.9 \\
Control/appeal & 53.3 & 57.8 & 48.9 \\
Control & 21.9 & 34.1 & 30.2 \\
\hline
\end{tabular}

Note: Prevalence of sustainable choices (\%), average of three weeks.

Table A2. Comparison of dynamics across treatments (difference-in-difference estimation).

\begin{tabular}{|c|c|c|}
\hline & $\mathbf{b}$ & $\mathbf{t}$ \\
\hline Pre-intervention & -0.0119 & $(-0.32)$ \\
\hline Intervention & 0.0164 * & $(2.03)$ \\
\hline Post-intervention & -0.0283 & $(-1.15)$ \\
\hline Feedback/high $\times$ pre-intervention & 0.0103 & $(0.19)$ \\
\hline Feedback/low $\times$ pre-intervention & -0.0426 & $(-0.81)$ \\
\hline Control/appeal $\times$ pre-intervention & 0.104 & $(1.97)$ \\
\hline Feedback/high $\times$ intervention & 0.0263 * & $(2.33)$ \\
\hline Feedback/low $\times$ intervention & -0.0304 * & $(-2.70)$ \\
\hline Control/appeal $\times$ intervention & $-0.0235 *$ & $(-2.08)$ \\
\hline Feedback/high $\times$ post-intervention & -0.0185 & $(-0.54)$ \\
\hline Feedback $/$ low $\times$ post-intervention & 0.0140 & $(0.41)$ \\
\hline Control/appeal $\times$ post-intervention & -0.0317 & $(-0.93)$ \\
\hline Constant & $0.346^{* *}$ & $(7.41)$ \\
\hline $\mathrm{R}_{\text {overall, }}^{2} \mathrm{R}_{\text {within }}^{2} \mathrm{R}_{\text {between }}^{2}$ & & \\
\hline
\end{tabular}

Note: Difference-in-difference fixed-effects regression with the proportion of sustainable choices at a given time period and location as dependent variable. Robust standard errors were used. The time periods were coded as splines. 55 aggregate observations, basing on a total of 162,523 purchase decisions. Reference categories: Control $\times$ pre-intervention, control $\times$ intervention, control $\times$ post-intervention. The data was provided by the cafeteria operator. ${ }^{*} p<0.05,{ }^{* *} p<0.001$; $\mathrm{t}$ statistics in parentheses. 

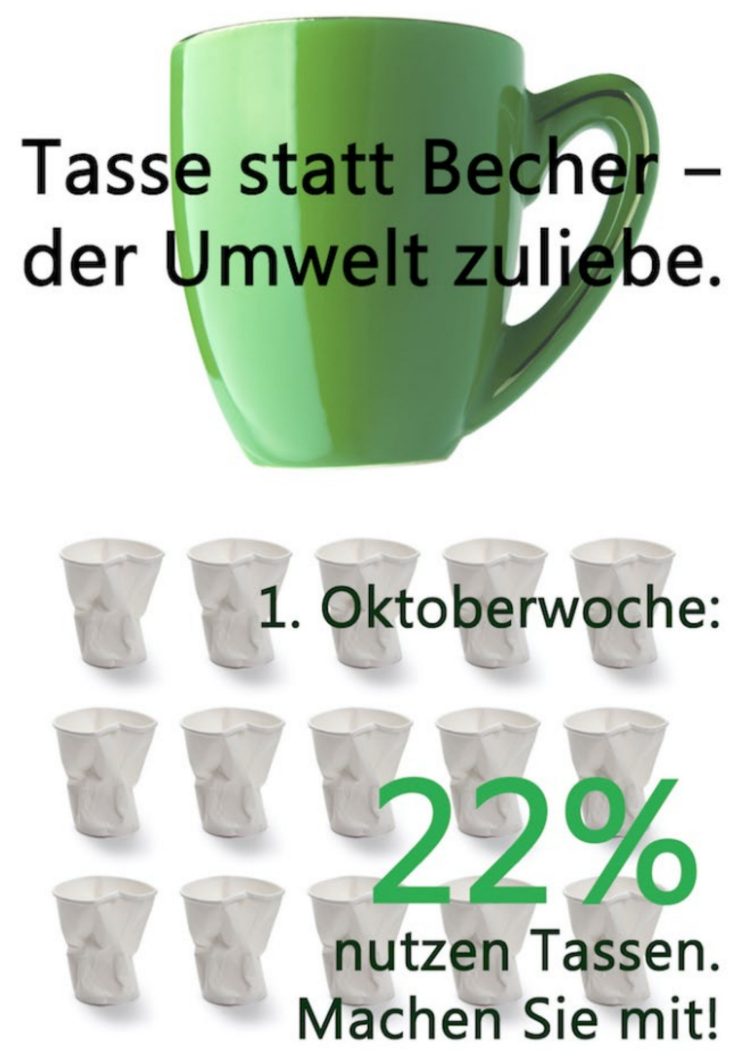

Figure A1. Sign used in the Feedback/high and Feedback/low treatments. A sign that was identical but for the normative feedback was used in the Control/appeal treatment.

\section{References}

1. Masson-Delmotte, V.; Zhai, P.; Pörtner, H.O.; Roberts, D.; Skea, J.; Shukla, P.R.; Pirani, A.; Moufouma-Okia, W.; Péan, C.; Pidcock, R.; et al. Summary for Policymakers. In Global Warming of $1.5^{\circ} \mathrm{C}$. An IPCC Special Report on the Impacts of Global Warming of $1.5^{\circ} \mathrm{C}$ above Pre-Industrial Levels and Related Global Greenhouse Gas Emission Pathways, in the Context of Strengthening the Global Response To the Threat of Climate Change, Sustainable Development, and Efforts to Eradicate Poverty; IPCC: Geneva, Switzerland, 2018.

2. Schiermeier, Q. Eat Less Meat: UN Climate-Change Report Calls for Change to Human Diet. Nature 2019, 572, 291-292. [CrossRef] [PubMed]

3. Otto, I.M.; Donges, J.F.; Cremades, R.; Bhowmik, A.; Hewitt, R.J.; Lucht, W.; Rockström, J.; Allerberger, F.; McCaffrey, M.; Doe, S.S.P.; et al. Social Tipping Dynamics for Stabilizing Earth's Climate by 2050. Proc. Natl. Acad. Sci. USA 2020, 117, $2354-2365$. [CrossRef]

4. Nyborg, K.; Anderies, J.M.; Dannenberg, A.; Lindahl, T.; Schill, C.; Schlüter, M.; Adger, W.N.; Arrow, K.J.; Barrett, S.; Carpenter, S.; et al. Social Norms as Solutions. Science 2016, 354, 42-43. [CrossRef] [PubMed]

5. Milkoreit, M.; Hodbod, J.; Baggio, J.; Benessaiah, K.; Calderón-Contreras, R.; Donges, J.F.; Mathias, J.D.; Rocha, J.C.; Schoon, M.; Werners, S.E. Defining Tipping Points for Social-Ecological Systems Scholarship-An Interdisciplinary Literature Review. Environ. Res. Lett. 2018, 13, 033005. [CrossRef]

6. Nyborg, K. No Man Is an Island: Social Coordination and the Environment. Environ. Resour. Econ. 2020, 76, 177-193. [CrossRef]

7. Westley, F.; Olsson, P.; Folke, C.; Homer-Dixon, T.; Vredenburg, H.; Loorbach, D.; Thompson, J.; Nilsson, M.; Lambin, E.; Sendzimir, J.; et al. Tipping toward Sustainability: Emerging Pathways of Transformation. Ambio 2011, 40, 762-780. [CrossRef]

8. Bicchieri, C. The Grammar of Society: The Nature and Dynamics of Social Norms; Cambridge University Press: Cambridge, UK, 2005; ISBN 9780511616037.

9. Coleman, J.S. Foundations of Social Theory; Belknap Press: Harvard, MA, USA, 1990.

10. Waring, T.M.; Goff, S.H.; Smaldino, P.E. The Coevolution of Economic Institutions and Sustainable Consumption via Cultural Group Selection. Ecol. Econ. 2017, 131, 524-532. [CrossRef]

11. Gössling, S.; Humpe, A.; Bausch, T. Does 'Flight Shame' Affect Social Norms? Changing Perspectives on the Desirability of Air Travel in Germany. J. Clean. Prod. 2020, 266. [CrossRef]

12. Capstick, S.B. Public Understanding of Climate Change as a Social Dilemma. Sustainability 2013, 5, 3484-3501. [CrossRef]

13. Irwin, T. Implications for Climate-Change Policy of Research on Cooperation in Social Dilemmas; Policy Research Working Paper 5006; Worldbank: Washington DC, USA, 2009; Volume 5006. 
14. Goeschl, T.; Kettner, S.E.; Lohse, J.; Schwieren, C. How Much Can We Learn about Voluntary Climate Action from Behavior in Public Goods Games? Ecol. Econ. 2020, 171, 106591. [CrossRef]

15. Milinski, M.; Semmann, D.; Krambeck, H.J.; Marotzke, J. Stabilizing the Earth's Climate Is Not a Losing Game: Supporting Evidence from Public Goods Experiments. Proc. Natl. Acad. Sci. USA 2006, 103, 3994-3998. [CrossRef]

16. Tavoni, A.; Dannenberg, A.; Kallis, G.; Löschel, A. Inequality, Communication, and the Avoidance of Disastrous Climate Change in a Public Goods Game. Proc. Natl. Acad. Sci. USA 2011, 108, 11825-11829. [CrossRef] [PubMed]

17. Hardin, G. The Tragedy of Commons. Science 1968, 162, 1243-1248.

18. Chaudhuri, A. Sustaining Cooperation in Laboratory Public Goods Experiments: A Selective Survey of the Literature. Exp. Econ. 2011, 14, 47-83. [CrossRef]

19. Fehr, E.; Gächter, S. Altruistic Punishment in Humans. Nature 2002, 415, 137-140. [CrossRef] [PubMed]

20. Fischbacher, U.; Gächter, S.; Fehr, E. Are People Conditionally Cooperative? Evidence from a Public Goods Experiment. Econ. Lett. 2001, 71, 397-404. [CrossRef]

21. Fehr, E.; Fischbacher, U. Third-Party Punishment and Social Norms. Evol. Hum. Behav. 2004, 25, 63-87. [CrossRef]

22. Bluffstone, R.; Dannenberg, A.; Martinsson, P.; Jha, P.; Bista, R. Cooperative Behavior and Common Pool Resources: Experimental Evidence from Community Forest User Groups in Nepal. World Dev. 2020, 129, 104889. [CrossRef]

23. Rustagi, D.; Stefanie, E.; Kosfeld, M. Conditional Cooperation and Costly Monitoring Explain Success in Forest Commons Management. Science 2010, 330, 961-965. [CrossRef]

24. Fehr, E.; Leibbrandt, A. A Field Study on Cooperativeness and Impatience in the Tragedy of the Commons. J. Public Econ. 2011, 95, 1144-1155. [CrossRef]

25. Chen, X.; Lupi, F.; He, G.; Liu, J. Linking Social Norms to Efficient Conservation Investment in Payments for Ecosystem Services. Proc. Natl. Acad. Sci. USA 2009, 106, 11812-11817. [CrossRef]

26. Bowles, S. Microeconomics: Behavior, Institutions and Evolution; Sage: New York, NY, USA, 2009.

27. Centola, D.M. Homophily, Networks, and Critical Mass: Solving the Start-up Problem in Large Group Collective Action. Ration. Soc. 2013, 25. [CrossRef]

28. Harsanyi, J.C.; Selten, R. A General Theory of Equilibrium Selection in Game; MIT Press: Cambridge, MA, USA, 1988.

29. Scheffer, M. Critical Transitions in Nature and Society; Princeton University Press: Princeton, NJ, USA, 2020.

30. Schelling, T.C. Hockey Helmets, Concealed Weapons, and Daylight Saving: A Study of Binary Choices With Externalities. J. Confl. Resolut. 1973, 17, 381-428. [CrossRef]

31. Granovetter, M. Threshold Models of Collective Behavior. Am. J. Sociol. 1978, 83, 1420-1443. [CrossRef]

32. Schelling, T.C. Micromotives and Macrobehavior; Norton: New York, NY, USA, 1978.

33. Young, H.P. Innovation Diffusion in Heterogeneous Populations: Contagion, Social Influence, and Social Learning. Am. Econ. Rev. 2009, 99, 1899-1924. [CrossRef]

34. Macy, M.W. Chains of Cooperation: Threshold Effects in Collective Action. Am. Sociol. Rev. 1991, 56, 730. [CrossRef]

35. Berger, J.; Efferson, C.; Vogt, S.; Efferson, C. Tipping Pro-Environmental Norm Diffusion at Scale-Opportunities and Limitations. Work. Pap. Univ. Bern 2021. Unpublished working paper.

36. Fleiß, J.; Ackermann, K.A.; Fleiß, E.; Murphy, R.O.; Posch, A. Social and Environmental Preferences: Measuring How People Make Tradeoffs among Themselves, Others, and Collective Goods. Cent. Eur. J. Oper. Res. 2020, 28, 1049-1067. [CrossRef]

37. Berger, J. Signaling Can Increase Consumers' Willingness to Pay for Green Products. Theoretical Model and Experimental Evidence. J. Consum. Behav. 2019, 18, 233-246. [CrossRef]

38. McElreath, R.; Bell, A.V.; Efferson, C.; Lubell, M.; Richerson, P.J.; Waring, T. Beyond Existence and Aiming Outside the Laboratory: Estimating Frequency-Dependent and Pay-off-Biased Social Learning Strategies. Philos. Trans. R. Soc. B Biol. Sci. 2008, 363, $3515-3528$. [CrossRef] [PubMed]

39. Richerson, P.J.; Boyd, R. Not by Genes Alone: How Culture Transformed Human Evolution; University of Chicago Press: Chicago, IL, USA, 2008.

40. Efferson, C.; Vogt, S.; Fehr, E. The Promise and the Peril of Using Social Influence to Reverse Harmful Traditions. Nat. Hum. Behav. 2020, 4, 55-68. [CrossRef]

41. Nyborg, K.; Rege, M. On Social Norms: The Evolution of Considerate Smoking Behavior. J. Econ. Behav. Organ. 2003, 52, 323-340. [CrossRef]

42. Jones, S. Dynamic Social Norms and the Unexpected Transformation of Women's Higher Education, 1965-1975. Soc. Sci. Hist. 2009, 33, 247-291. [CrossRef]

43. Centola, D.; Becker, J.; Brackbill, D.; Baronchelli, A. Experimental Evidence for Tipping Points in Social Convention. Science 2018, 360, 1116-1119. [CrossRef] [PubMed]

44. Andreoni, J.; Nikiforakis, N.; Siegenthaler, S. Predicting Social Tipping and Norm Change in Controlled Experiments; NBER Working Paper; National Bureau of Economic Research: Cambridge, MA, USA, 2020.

45. Castilla-Rho, J.C.; Rojas, R.; Andersen, M.S.; Holley, C.; Mariethoz, G. Social Tipping Points in Global Groundwater Management. Nat. Hum. Behav. 2017, 1, 640-649. [CrossRef]

46. Mathias, J.D.; Anderies, J.M.; Baggio, J.; Hodbod, J.; Huet, S.; Janssen, M.A.; Milkoreit, M.; Schoon, M. Exploring Non-Linear Transition Pathways in Social-Ecological Systems. Sci. Rep. 2020, 10, 4136. [CrossRef] 
47. Chen, X.; Lupi, F.; An, L.; Sheely, R.; Viña, A.; Liu, J. Agent-Based Modeling of the Effects of Social Norms on Enrollment in Payments for Ecosystem Services. Ecol. Modell. 2012, 229, 16-24. [CrossRef] [PubMed]

48. Richter, A.; van Soest, D.; Grasman, J. Contagious Cooperation, Temptation, and Ecosystem Collapse. J. Environ. Econ. Manag. 2013, 66, 141-158. [CrossRef]

49. Richter, A.; Grasman, J. The Transmission of Sustainable Harvesting Norms When Agents Are Conditionally Cooperative. Ecol. Econ. 2013, 93, 202-209. [CrossRef]

50. Novoradovskaya, E.; Mullan, B.; Hasking, P.; Uren, H.V. My Cup of Tea: Behaviour Change Intervention to Promote Use of Reusable Hot Drink Cups. J. Clean. Prod. 2020, 284, 124675. [CrossRef]

51. Suskevice, V.; Grönman, K. Single-Use Paper Cups Circularity Improvement and Environmental Impact Mitigation Measures for Lappeenranta University of Technology Campus. Multidiscip. Digit. Publ. Inst. Proc. 2019, 16, 6058. [CrossRef]

52. Cialdini, R.B.; Reno, R.R.; Kallgren, C.A. A Focus Theory of Normative Conduct: Recycling the Concept of Norms to Reduce Littering in Public Places. J. Pers. Soc. Psychol. 1990, 58, 1015-1026. [CrossRef]

53. Berger, J.; Hevenstone, D. Norm Enforcement in the City Revisited: An International Field Experiment of Altruistic Punishment, Norm Maintenance, and Broken Windows. Ration. Soc. 2016, 28, 299-319. [CrossRef]

54. Przepiorka, W.; Berger, J. The Sanctioning Dilemma: A Quasi-Experiment on Social Norm Enforcement in the Train. Eur. Sociol. Rev. 2016, 32, 439-451. [CrossRef]

55. Fehr, E.; Fischbacher, U. The Nature of Human Altruism. Nature 2003, 425, 785-791. [CrossRef]

56. Bergquist, M.; Nilsson, A.; Schultz, W.P. A Meta-Analysis of Field-Experiments Using Social Norms to Promote pro-Environmental Behaviors. Glob. Environ. Chang. 2019, 59, 101941. [CrossRef]

57. Bergquist, M. Most People Think They Are More Pro-Environmental than Others: A Demonstration of the Better-than-Average Effect in Perceived Pro-Environmental Behavioral Engagement. Basic Appl. Soc. Psych. 2020, 42, 50-61. [CrossRef]

58. Bergquist, M.; Nilsson, A. I Saw the Sign: Promoting Energy Conservation via Normative Prompts. J. Environ. Psychol. 2016, 46, 23-31. [CrossRef]

59. Schultz, P.W.; Nolan, J.M.; Cialdini, R.B.; Goldstein, N.J.; Griskevicius, V. The Constructive, Destructive, and Reconstructive Power of Social Norms: Research Article. Psychol. Sci. 2007, 18, 429-434. [CrossRef]

60. Wallen, K.E.; Kyle, G.T. The Efficacy of Message Frames on Recreational Boaters' Aquatic Invasive Species Mitigation Behavioral Intentions. Hum. Dimens. Wildl. 2018, 23, 297-312. [CrossRef]

61. Marsh, L.; Cormier, D. Spline Regression Models. In Regression Analysis in Medical Research; Springer: Cham, Switzerland, 2011; pp. 267-277. [CrossRef]

62. Nisa, C.F.; Bélanger, J.J.; Schumpe, B.M.; Faller, D.G. Meta-Analysis of Randomised Controlled Trials Testing Behavioural Interventions to Promote Household Action on Climate Change. Nat. Commun. 2019, 10, 4545. [CrossRef] [PubMed]

63. Angrist, J.D.; Pischke, J.-S. Mostly Harmless Econometrics; Princeton University Press: Princeton, NJ, USA, 2019.

64. Shadish, W.R.; Cook, T.D. Quasi-Experimental Designs for Generalized Causal Inference; Houghton Mifflin: Boston, MA, USA, 2008; ISBN 0395615569.

65. Farrow, K.; Grolleau, G.; Ibanez, L. Social Norms and Pro-Environmental Behavior: A Review of the Evidence. Ecol. Econ. 2017, 140, 1-13. [CrossRef]

66. Richter, I.; Thøgersen, J.; Klöckner, C.A. A Social Norms Intervention Going Wrong: Boomerang Effects from Descriptive Norms Information. Sustainability 2018, 10, 2848. [CrossRef]

67. Bicchieri, C.; Xiao, E. Do the Right Thing: But Only If Others Do So. J. Behav. Decis. Mak. 2009, 22, 191-208. [CrossRef]

68. Scheffer, M.; Bascompte, J.; Brock, W.A.; Brovkin, V.; Carpenter, S.R.; Dakos, V.; Held, H.; Van Nes, E.H.; Rietkerk, M.; Sugihara, G. Early-Warning Signals for Critical Transitions. Nature 2009, 461, 53-59. [CrossRef]

69. Dakos, V.; Carpenter, S.R.; Brock, W.A.; Ellison, A.M.; Guttal, V.; Ives, A.R.; Kéfi, S.; Livina, V.; Seekell, D.A.; van Nes, E.H.; et al. Methods for Detecting Early Warnings of Critical Transitions in Time Series Illustrated Using Simulated Ecological Data. PLOS ONE 2012, 7, e41010. [CrossRef]

70. Bauch, C.T.; Sigdel, R.; Pharaon, J.; Anand, M. Early Warning Signals of Regime Shifts in Coupled Human-Environment Systems. Proc. Natl. Acad. Sci. USA 2016, 113, 14560-14567. [CrossRef] [PubMed]

71. Scheffer, M. Complex Systems: Foreseeing Tipping Points. Nature 2010, 467, 411-412. [CrossRef] [PubMed]

72. Louviere, J.J.; Hensher, D.A.; Swait, J.D. Frontmatter. In Stated Choice Methods: Analysis and Applications; Cambridge University Press: Cambridge, UK, 2000; ISBN 0521788307.

73. Camerer, C.F.; Fehr, E. Measuring Social Norms and Preferences Using Experimental Games: A Guide for Social Scientists. In Foundations of Human Sociality: Economic Experiments and Ethnographic Evidence from Fifteen Small-Scale Societies; Henrich, J., Ed.; Oxford University Press: Oxford, UK, 2005; ISBN 9780191601637. 